\title{
TIC E CURRÍCULO - UMA CONJUGAÇÃO POSSÍVEL
}

Jéssica Zacarias de Andrade - PUC Rio - professorajessica@yahoo.com.br Gilda Helena Bernardino de Campos - PUC Rio - gilda@ccead.puc-rio.br

\begin{abstract}
Resumo
O presente artigo procura refletir acerca da conjugação entre o currículo e as TIC por intermédio da chamada pedagogia de projetos. A partir da análise da unidade curricular Currículo, projetos e tecnologias do curso Tecnologias na Educação: ensinando e aprendendo com as TIC (100h), do Programa Nacional de Formação Continuada em Tecnologia Educacional (ProInfo Integrado), procura-se depreender e discutir a proposta de inserção das tecnologias da informação e comunicação (TIC) nas escolas públicas brasileiras, seu vínculo com a pedagogia de projetos - explicitando suas principais características constituintes - e a viabilidade de apropriação e incorporação pela estrutura curricular escolar. A atualização constante e ininterrupta se apresenta como condição sine qua non na formação dos professores inseridos no contexto da chamada sociedade do conhecimento, onde a construção do conhecimento pelos alunos - através da mediação do professor como um orientador e problematizador - e o trabalho colaborativo, surgem como pilares de um novo paradigma na educação.
\end{abstract}

Palavras-chave: TIC e Educação, TIC e Currículo, Formação Continuada de Professores.

\section{ICT AND CURRICULUM: A POSSIBLE COMBINATION}

\begin{abstract}
This article aims to reflect on the conjunction between the curriculum and ICT through the project pedagogy. From the analysis of the unit Curriculum, projects and technologies, part of the course Technologies in Education: Teaching and Learning with ICT (100h), included in the National Program for Continuing Education in Educational Technology (ProInfo Integrado), seeks to infer and discuss the insertion of Information and Communication Technologies (ICT) in Brazilian public schools and the project pedagogy, explaining its main features and the feasibility into the school curriculum. The continuous teachers training appears as a sine qua non condition in the for the-so-called knowledge society, where the construction of the students' knowledge - through the pedagogical mediation, arises as pillars of a new paradigm in education.
\end{abstract}

Keywords: ICT and Education, ICT and Curriculum, Continuing Teacher Training. 


\section{Introdução}

A partir do panorama traçado com o advento da chamada sociedade/economia do conhecimento - sobre a qual nos deteremos especificamente na primeira sessão do presente artigo - fica clara a necessidade de integração das TIC de maneira definitiva ao universo escolar. Atendendo a esta demanda, em 2007, a Secretaria de Educação à Distância elaborou o Programa Nacional de Tecnologia Educacional (PROINFO) - em consonância com o Plano de Desenvolvimento da Educação (PDE) - o qual postulava a integração e articulação de três componentes: a instalação de ambientes tecnológicos nas escolas públicas, formação continuada dos profissionais da educação - rede pública - para o uso das TIC e disponibilização de conteúdos e recursos educacionais multimídia e digitais, soluções e sistemas de informação. Neste contexto, surge o Programa Nacional de Formação Continuada em Tecnologia Educacional (ProInfo Integrado) que congrega um conjunto de processos formativos, dentre eles o curso Introdução à Educação Digital (40h), o curso Tecnologias na Educação: Ensinando e Aprendendo com as TIC (100h) e o curso Elaboração de Projetos (40h). Seu principal objetivo é a inserção das TIC nas escolas públicas brasileiras, visando a promoção da inclusão digital da comunidade escolar e a dinamização e qualificação dos processos de ensino-aprendizagem com vistas à melhoria da qualidade da educação básica.

O curso Tecnologias na Educação: Ensinando e Aprendendo com as TIC (100h) - do qual trataremos especificamente da terceira unidade na segunda sessão deste artigo - é apresentado como uma aventura fascinante que pretende levar o cursista a refletir sobre as características da época vigente - a sociedade do conhecimento -, tomar consciência do papel da tecnologia na vida cotidiana, compreender a construção do conhecimento na sociedade da informação e descobrir como participar mais efetivamente desse processo e como inseri-lo em sua ação profissional de educador. Os pressupostos básicos do curso são a utilização da experiência prática de sala de aula do cursista e a construção coletiva do conhecimento. O objetivo primordial é oferecer subsídios teórico-metodológicopráticos que permitam aos cursistas compreender o potencial pedagógico das TIC, utilizando-as em sua prática - através do planejamento de estratégias de ensino integrados a recursos tecnológicos - com a promoção de situações de ensino que aprimorem a aprendizagem dos alunos, levando-os a construção do conhecimento e habilidades esperados, à criatividade e ao trabalho colaborativo. Para realizar esta empreitada, o curso propõe a chamada pedagogia de projetos - melhor analisada na segunda sessão deste artigo -, que segundo Prado (2005) deve permitir que o aluno aprenda fazendo e reconheça a própria autoria naquilo que produz por meio de questões de investigação que lhe impulsionam a contextualizar conceitos já conhecidos e descobrir outros que emergem durante o desenvolvimento do projeto.

Nesta mesma direção, a UNESCO apresenta em 2009 o documento Padrões de Competência em TIC para Professores - com propostas que se assimilam às do curso oferecido pelo ProInfo Integrado -, respondendo às suas funções enquanto agência que estabelece padrões, seus mandatos no Programa de Educação para Todos e como agência líder nas linhas de ação C4 em capacitação com o PNUD - e C7 em aprendizagem eletrônica com a CMSI - Cúpula Mundial da Sociedade da Informação e seu esforço para construir sociedades de conhecimento inclusivas por meio da comunicação e informação. Em suma, a construção do conhecimento pelos alunos, através da mediação do professor, traz à tona as temáticas da problematização e da autonomização no processo de ensinoaprendizagem. Assim como a ideia de uma construção coletiva deste conhecimento, traz em seu escopo a proposta dos grupos colaborativos e das organizações de aprendizagem. Estes quatro pilares de um novo paradigma da educação são tratados na terceira sessão deste artigo. 


\section{A sociedade/economia do conhecimento}

Atualmente, as expressões sociedade do conhecimento ou economia do conhecimento são bastante utilizadas quando se discute temas como educação e tecnologia. Entretanto, antes de explicitar os possíveis significados da(s) mesma(s), é relevante uma apresentação do que a sociedade contemporânea entende por conhecimento para se adjetivar de tal forma. Para Sanchez, Heene e Thomas (1996) o conhecimento é o conjunto de crenças mantidas por um indivíduo acerca de relações causais entre fenômenos. Para Fleury e Oliveira Junior (2001), o conhecimento pode ser entendido como um conjunto de informações associadas à experiência, à intuição e aos valores. Nonaka e Takeuchi (1997) apresentam uma distinção entre dois tipos básicos de conhecimento: o explícito ou codificado - de natureza objetiva, transmissível em linguagem formal, sistemática - e o tácito - de natureza subjetiva, profundamente enraizado na ação, no comprometimento e no envolvimento em um contexto específico, o que dificulta sua formalização e comunicação.

A partir das definições propostas acima, é possível iniciar o percurso para uma melhor compreensão da expressão sociedade/economia do conhecimento - tomando-a como um novo paradigma de sociedade - discutindo o que realmente esta quer designar assim como suas implicações para a educação. Para tanto, é interessante a análise da abordagem feita por David Guile (2008), recuperando a tradição sociológica insuficiente do seu ponto de vista - acerca da teorização a respeito desta temática. Bell e Castells apud Guile (2008) definiram a economia do conhecimento, em termos de conhecimento, como principal fator da produção e a tecnologia como seu principal recurso, concordando que o conhecimento tem importância fundamental para o desenvolvimento econômico das sociedades industriais avançadas. Enquanto Bell (apud Guile, 2008) se concentra na contribuição da tecnologia intelectual - ou seja, aplicação da ciência como estímulo - para o desenvolvimento econômico, Castells apud Guile (2008) concentra-se na valorização da tecnologia da ciência enquanto Tecnologia da Informação e Comunicação e seu impacto na sociedade, preocupando-se com a aplicação tecnológica da ciência na forma de TIC e com a aplicação dos dados gerados pela mesma.

Gibbons apud Guile (2008) defende a distinção entre dois modos de conhecimento: o Modo 1, que se refere a pesquisa vinculada às disciplinas do conhecimento realizadas na universidade e o Modo 2, que se refere aos modos de conhecimento heterogêneos e transdiciplinares criados em contextos de aplicação, caracterizados por um fluxo constante entre o teórico e o prático. O modo 2 de conhecimento seria portanto uma mistura de componentes codificados e tácitos, distinção cunhada por Polanyi apud Guile (2008) e apropriada por Nonaka e Takeushi (1997). Gibbons aposta em uma supremacia do conhecimento tácito, pois este atribuiria às empresas vantagem competitiva na economia global. Já Nonaka e Takeushi defendem o conhecimento, criado por profissionais e não somente cientistas, que facilitam uma espiral de interações entre o conhecimento explícito e o conhecimento tácito.

Em suma, pode-se constatar a primazia do conhecimento teórico no pensamento tradicional de Bell e Castells em contraposição ao pensamento contemporâneo de Gibbons, Nonaka e Takeushi que apontam o conhecimento tácito como recurso primordial da produção de conhecimento. Esta distinção esclarece bem como o paradigma contemporâneo de sociedade/economia do conhecimento se constituiu e em que bases ele está assentado, o que indica em termos de implicações na educação, que a mesma deverá se estruturar de forma mais pragmática e menos teórica. Esta concepção da educação fica clara no documento da UNESCO - Padrões de Competência em TIC para Professores quando este afirma que: 
Para viver, aprender e trabalhar bem em uma sociedade cada vez mais complexa, rica em informação e baseada em conhecimento, os alunos e professores devem usar a tecnologia de forma efetiva, pois em um ambiente educacional qualificado, a tecnologia pode permitir que os alunos se tornem: usuários qualificados das tecnologias da informação; pessoas que buscam, analisam e avaliam a informação; solucionadores de problemas e tomadores de decisões; usuários criativos e efetivos de ferramentas de produtividade; comunicadores, colaboradores, editores e produtores; cidadãos informados, responsáveis e que oferecem contribuições.

\section{Currículo, projetos e tecnologias: a proposta do proinfo integrado}

Para compreender os objetivos desta unidade do curso Tecnologias na Educação: Ensinando e Aprendendo com as TIC (100h) é importante apresentá-los e discuti-los individualmente, analisando sua constituição e propostas de concretização. $O$ primeiro objetivo consiste em contextualizar a temática tratada na unidade a partir das contribuições das tecnologias digitais ao desenvolvimento de projetos. Neste ponto é importante explicitar o significado do termo projeto $^{1}$, que envolve a antecipação de algo desejável que ainda não foi realizado, pensar uma realidade que ainda não aconteceu. $\mathrm{O}$ projeto é uma construção própria do ser humano que se concretiza a partir de uma descrição inicial de um conjunto de atividades, cuja realização produz um movimento no sentido de buscar no futuro, uma nova situação que responda às suas indagações ou caminhe no sentido de melhor compreendê-las.

Posto isto, a contextualização da temática se realiza a partir de uma entrevista feita com Pedro Demo intitulada Os desafios da linguagem no século XXI para a aprendizagem na escola, na qual o autor instiga a reflexão sobre o desafio da superação do descompasso entre a cultura cotidiana do aprendiz e aquela vivenciada na escola. Dentre outras questões, o autor alerta que as novas alfabetizações estão entrando em cena, e o Brasil não está dando muita importância a isso, afirmando que estamos encalhados no processo do ler, escrever e contar; em uma escola, onde a criança escreve porque tem que copiar do quadro ao passo que na internet, esta escreve porque quer interagir com o mundo. Outras contribuições são a defesa da ideia de aprendizagem situada - um aprendizado de tal maneira que apareça sempre na vida da criança -, e da concepção de linguagens multimodais - como por exemplo a ideia de um texto hoje, já tem várias coisas inclusas: som, imagem, texto, animação. Por fim o autor ressalta que a escola precisa se restaurar para se situar nas habilidades do século XXI e o caminho para isso é cuidar do professor, porque segundo ele, todas as mudanças só entram bem na escola se entrarem pelo professor: ele é a figura fundamental, não há como substituir o professor; ele é a tecnologia das tecnologias, e deve se portar como tal. As ideias defendidas por Demo subsidiam e justificam a opção do curso em trabalhar por meio da pedagogia de projetos, que para seus autores, é a abordagem pedagógica adequada à integração da realidade do aprendiz ao currículo trabalhado na escola.

Esta contextualização é seguida de uma proposta de atividade - a primeira da unidade - de reflexão sobre a prática docente do cursista, uma espécie de auto-análise necessária para a realização da segunda atividade da unidade, onde se propõe colocar a

\footnotetext{
${ }^{1}$ Definição extraída do material impresso - Unidade 3: Currículo, projetos e tecnologias - do curso Tecnologias na Educação: Ensinando e Aprendendo com as TIC (100h), página 148.
} 
teoria em prática, ou seja, o cursista - a partir da leitura de estratégias compartilhadas no fórum do ambiente virtual de aprendizagem - deve planejar e executar uma atividade junto a seus alunos, a partir de suas necessidades de aprendizagem, integrando tecnologias que facilitem sua percepção da realidade. Posteriormente ele deve avaliar alguns aspectos da prática, tais como, a necessidade de modificações ou adaptações, novas ideias ou aprimoramentos surgidos na ação, o atingimento ou não dos objetivos propostos. Com isso o objetivo do curso - e mais especificamente desta unidade do mesmo - de se preparar o escopo de um projeto, se materializa. A ideia de grupos colaborativos - concepção a ser discutida na última sessão deste artigo - é presente no curso não só através do fórum de discussão como também dos portfólios criados pelos cursistas - onde relatam as experiências realizadas a partir das atividades propostas - posteriormente postados no $b \log$, o que permite a interação e troca de experiências.

O segundo objetivo é propiciar o planejamento e a aplicação de ações na perspectiva da pedagogia por meio de projetos. A partir da concepção de projeto supracitada, entende-se a pedagogia de projetos como aquela segundo a qual a aprendizagem do aluno é favorecida por meio de uma abordagem construcionista - a construção do conhecimento acontece na realização de uma ação concreta que produz algo palpável, de interesse de quem produz - que se utiliza de recursos tecnológicos. A intenção é fazer com que o aluno busque informações ou as extraia de experiências em curso ou vivências anteriores, facilitando o processo de atribuição de significados às diferentes situações com as quais se confrontam. A abordagem construcionista defende então uma aprendizagem significativa, através da qual o aluno seja capaz de selecionar e articular informações, tomar decisões, trabalhar em grupo, gerenciar o confronto de ideias, aprender colaborativamente com seus pares, fazer indagações, levantar dúvidas, estabelecer relações com aquilo que já sabe e descobrir ideias e novas compreensões. $\mathrm{O}$ papel do professor nessa abordagem pedagógica é entender o mundo do aluno através do diálogo, identificando o conhecimento que ele traz do cotidiano; orientando-o para que ele possa ter acesso a informações em diferentes fontes a fim de atribuir-lhes significado e construir conhecimento, assim como auxiliá-lo na reconstrução de significados e formalização do conhecimento científico.

Visando elucidar o planejamento e aplicação de ações por meio da pedagogia de projetos, é proposta a leitura do artigo Blog, wiki e mapas conceituais digitais no desenvolvimento de Projetos de Aprendizagem com alunos do Ensino Fundamental (DUTRA, PICCININI, BECKER, JOHANN E FAGUNDES, 2006). Neste artigo os autores fazem um relato do funcionamento do Projeto Amora, do Colégio de Aplicação da UFRGS que tem por objetivo o desenvolvimento da autonomia - a discussão de autonomização do processo de ensino-aprendizagem é feita mais detalhadamente na sessão a seguir - e criatividade dos alunos. Com os projetos de aprendizagem, os alunos desenvolvem pesquisas a respeito de temas científicos, aliando os objetivos mencionados anteriormente ao uso de ferramentas de interação e intervenção suportadas por tecnologia e o uso de três ferramentas digitais: blogs, mapas conceituais e wiki. Na sequência, o cursista é convidado à experimentação da pedagogia de projetos na sala de aula com a integração das TIC ao currículo. O objetivo da atividade é aplicar o conjunto de aprendizagens construídas durante o curso acerca das TIC na educação, como possibilidade de inovar a prática educativa, ultrapassar os limites da sala de aula e dos conteúdos programáticos. O tempo é tratado como variável fundamental na elaboração do projeto e a interdisciplinaridade- vista como uma categoria de ação, ou seja, a efetiva integração das disciplinas na prática - o caminho para a construção do currículo como um elemento que reconhece o conhecimento em sua globalidade - tópico a ser discutido no terceiro objetivo da unidade. Em suma, o projeto deve explicitar quais conhecimentos se 
espera construir, reconhecer os conhecimentos prévios - certezas provisórias nas palavras de Fagundes et al. (2006) -, indicar as estratégias e recursos de aula assim como recursos complementares e apresentar a(s) formas(s) de avaliação do desenvolvimento dos alunos com o mesmo.

O terceiro objetivo é identificar as características do currículo construído por meio do desenvolvimento de projetos, com uso de tecnologias. A elaboração de um currículo depende diretamente da concepção de conhecimento, ensino e aprendizagem que se tem. $\mathrm{O}$ currículo tem sido orientado historicamente à transmissão de conhecimentos socialmente válidos e resultantes de uma seleção organizada intencionalmente com o objetivo de que o aluno alcance determinados resultados. O curso defende que o desenvolvimento do currículo, na realidade da escola e do contexto da sala de aula, vai além das grades curriculares, envolvendo toda a escola, o seu entorno, a vida dos alunos, os acontecimentos locais e globais que são variáveis intervenientes no sistema de relações estabelecido na dinâmica do processo de ensino-aprendizagem. A integração das TIC permite interligar essas duas vertentes em novas práticas pedagógicas com o uso da internet e web, proporcionando a expansão das situações de aprendizagem e englobando a complexidade crescente do conhecimento, da ciência e da tecnologia. A característica principal de um currículo que aposte na pedagogia de projetos é a flexibilização, o currículo passa ter uma visão mais ampla e integradora entre os conhecimentos sistematizados e aceitos socialmente e os conhecimentos que emergem do contexto, na vida das pessoas, nas diferentes linguagens de comunicação que fazem parte de uma cultura. Nesta perspectiva, durante o desenvolvimento de um projeto o aluno tem a oportunidade de recontextualizar conceitos e estratégias, estabelecendo relações significativas entre as várias áreas do conhecimento. O professor, por sua vez, deve adotar uma postura de observação e análise - professor pesquisador ou professor reflexivo - sobre as necessidades conceituais que emergem no desenrolar do projeto e desenvolver estratégias pedagógicas que possibilitem o aprendizado do aluno, tanto no sentido da abrangência - quando diversos componentes curriculares e as tecnologias se articulam como no sentido do aprofundamento - no que se refere às particularidades de uma área/disciplina do currículo. Isto deixa claro que a postura interdisciplinar dos projetos não elimina as disciplinas como um corpo organizado de conhecimentos, mas estes podem se integrar a conhecimentos de outras disciplinas no estudo de um mesmo fenômeno. $\mathrm{O}$ uso das tecnologias permite o retorno à visão de conhecimento em sua unicidade, por meio do estabelecimento de ligações em redes que integram ideias, conceitos, experiências e padrões, reafirmando a relatividade da ciência e da noção de espaço-tempo.

O quarto e último objetivo é propiciar a identificação das concepções de currículo e sua ressignificação diante das possibilidades de integração da escola com diferentes espaços de produção do conhecimento. O curso trabalha com o conceito de currículo na perspectiva de situá-lo historicamente, tratando-o assim como conhecimento organizado, sistematizado, aceito socialmente, selecionado em estruturas previamente concebidas, mas também como o conhecimento que o aluno traz de seu contexto, da vida, mas que não se limita ao conhecimento cotidiano - o chamado conhecimento tácito - até porque esse aluno também traz consigo conhecimento codificado. O currículo não se configura apenas como uma lista de conteúdos prontos a serem transmitidos aos alunos e não se esgota na aplicação do conhecimento no cotidiano. A divisão entre as disciplinas não é estática e ocorre à medida que se aprofundam os conhecimentos de determinada área cuja compreensão exige estudos especializados. Com a intensificação do processo de especialização, os vínculos entre as disciplinas foram se perdendo e cada uma passou a ser ministrada de forma isolada sob a ótica de um corpo teórico que também foi perdendo 
sua ligação com a prática, tudo isso consubstanciado por uma estrutura de sistema de ensino que se apoia em um quadro de professores e de horários pré-estabelecidos para cada disciplina. Entretanto, a pedagogia de projetos carrega consigo a necessidade da criação de uma nova cultura educacional, onde a utilização das tecnologias potencializa a construção de redes de conhecimento e comunicação, transformando-se em ferramenta para a compreensão e resolução de problemas da realidade. Esta nova visão educacional, com o uso das TIC no desenvolvimento de projetos, vislumbra a escola como espaço privilegiado de interação social quando integrada a outros espaços de produção do conhecimento, pois o diálogo é facilitado quando se constrói um currículo com base na ação - identificado através das diferentes formas de registro digital.

Nesta perspectiva é proposta a última atividade da unidade: uma reflexão sobre o conceito de currículo e o processo de integração das TIC a este. Os cursistas devem avaliar se conteúdos presentes no projeto estão inseridos no currículo formal, inferir conceitos, atitudes e procedimentos desenvolvidos no projeto e se os mesmos estão inseridos no currículo, identificar se e como os alunos absorveram o uso das TIC como parte constituinte do currículo para finalmente chegar a sua própria definição de currículo.

\section{Problematização, autonomização, grupos colaborativos e organizações de aprendizagem: um novo paradigma na educação}

A partir da proposta do curso de 100h do Proinfo Integrado e mais especificamente da unidade curricular analisada na sessão anterior, é notória a defesa do que denominamos os quatro pilares de um novo paradigma em educação: a problematização, a autonomização, os grupos colaborativos, e as organizações de aprendizagem. No que se refere à problematização, apesar de não ser algo eminentemente inovador já que especialistas da educação como John Dewey e Paulo Freire defenderam-na como uma etapa e/ou ferramenta fundamental no processo de ensino-aprendizagem há muito tempo, esta surge na sociedade vigente não como uma alternativa para a educação, mas sim como um pilar de sustentação do novo paradigma de educação em uma sociedade/economia do conhecimento. Para prosseguir com a discussão julgamos procedente levantar algumas definições/concepções de problematização.

A habilidade de problematizar foi definida por Zanotto e De Rose (2003) como a habilidade de relacionar de forma coerente e sequencial três momentos: identificação de um problema, busca de explicação e proposição de soluções. Problematizar, portanto, seria mais do que tão somente formular questões ou perguntas, como se encontra no léxico, porque nem toda pergunta contém um problema. Problematizar significa ser capaz de responder ao conflito que o problema traz de forma intrínseca e que o sustenta ou, nas palavras de Paviani apud Zanotto e De Rose (2003) é a necessidade de solução de conflitos que marca e delimita o problema.

A proposta de Dewey visava que o sujeito fosse ativo no seu processo de problematizar pois o aluno deveria ter uma situação autêntica de experiência, na qual estivesse interessado; as atividades deveriam ter propósitos definidos; o pensamento deveria ser estimulado; o aluno deveria observar para utilizar as informações e instrumentos; o resultado do trabalho deveria ser algo concreto; o aluno deveria ter a oportunidade de comprovar as ideias que tenha tido, por meio da sua aplicação (NÉRICI apud ZANOTTO e DE ROSE, 2003).

A pedagogia freireana apresenta três dimensões que constituem sua concepção de teoria de conhecimento: a leitura de mundo, a tematização e a problematização. Nesta concepção 
o que está sendo enfatizado é o sujeito práxico: a ação de problematizar acontece a partir da realidade que cerca o sujeito; a busca de explicação e solução visa a transformar aquela realidade, pela ação do próprio sujeito (sua práxis). O sujeito, por sua vez, também se transforma na ação de problematizar e passa a detectar novos problemas na sua realidade e assim sucessivamente. (ZANOTTO e DE ROSE, 2003)

As três concepções apresentadas se aproximam e se complementam e fornecem os elementos necessários para compreender melhor a proposta de uma pedagogia de projetos baseada em uma abordagem construcionista que toma a metodologia da problematização como ponto de partida da prática docente.

No documento da UNESCO - Padrões de Competência em TIC para Professores, a proposta é um pouco diferente, não se trata de problematizar a realidade, mas sim de uma aprendizagem baseada em problemas ${ }^{2}$ - proposta curricular onde os problemas de ensino são elaborados por uma equipe de especialistas para cobrir todos os conhecimentos essenciais do currículo - como um instrumento importante para o aprofundamento do conhecimento, para a apropriação da tecnologia, após a inserção da mesma na escola através da capacitação dos professores - a alfabetização em tecnologia. Para tanto é necessária uma mudança na avaliação, trazendo em seu escopo a proposta de que a mesma deve se concentrar na solução de problemas complexos e se incorporar nas atividades de sala de aula. A pedagogia de sala de aula deve incluir o aprendizado colaborativo com base em problemas e projetos. $\mathrm{O}$ aprendizado colaborativo ou os grupos colaborativos se configuram - na perspectiva tanto da UNESCO quanto do ProInfo Integrado -, na construção coletiva do conhecimento e no trabalho em rede. $\mathrm{O}$ foco do processo de ensino-aprendizagem é no aluno e o professor assume um papel de mediador, orientador e facilitador. Neste momento, apesar da proposta do foco no aluno, ainda não há uma proposta de autonomização do mesmo - o que também não ocorre no caso do ProInfo Integrado -, mas sim de uma parte do processo de ensino-aprendizagem, como por exemplo a autonomização da estrutura curricular e de avaliação. Na proposta da UNESCO é o professor que estrutura as questões-problema, baseadas em problemas do mundo real - metas políticas e prioridades sociais -, mas não especificamente dos problemas da realidade dos alunos, como proposto pelo ProInfo Integrado, que defende a problematização para além de uma aprendizagem baseada em problemas.

Por último os dois pilares que se encontram na condição de consequência dos processos de implementação e consolidação da metodologia de problematização e dos grupos colaborativos na escola: a autonomização - do aluno, especificamente - e as organizações de aprendizagem. Segundo o documento da UNESCO - e pode-se inferir o mesmo da proposta do ProInfo Integrado - os professores precisam estar preparados para oportunizar autonomia aos alunos com as vantagens que a tecnologia pode trazer. Para tanto o professor primeiramente tem que passar, ele mesmo, por um processo de autonomização em relação às TIC - na alfabetização digital - para então ser mediador no processo de autonomização do aluno - na apropriação da tecnologia, com o aprofundamento do conhecimento da mesma. Este processo de autonomização do aluno se concretiza quando há a incorporação da tecnologia e se cria conhecimento com ela. Seria no momento em que os alunos estabelecessem suas próprias metas e planos de aprendizagem, entendidos como a habilidade de definir o que já sabem, avaliar competências e deficiências, elaborar planos de aprendizagem, permanecer na tarefa,

${ }^{2}$ Definição de BERBEL, N.A.N. em "A problematização e a aprendizagem baseada em problemas: diferentes termos ou diferentes caminhos?”. Interface, Comunic, Saúde, Educ, 2, Fev de 1998. 
verificar seu próprio progresso e se basear nos sucessos para corrigir falhas. Com isso, o professor teria a função de modelar esses processos, construindo assim comunidades de aprendizagem nas salas de aula, onde os alunos estão permanentemente envolvidos na construção de suas próprias habilidades de aprendizagem, partilhando do desenvolvimento destas com seus pares. A consequência disso é a elevação da escola ao patamar de uma organização de aprendizagem, com o envolvimento de todos os atores no processo de ensino-aprendizagem. Neste momento além de se utilizar das TIC na sala de aula e como apoio aos projetos colaborativos, devem ser criados dispositivos de rede, recursos digitais e ambientes eletrônicos como apoio à comunidade na produção do conhecimento e ao aprendizado colaborativo sem importar o momento e o lugar.

\section{Conclusão}

A proposta geral da unidade curricular Currículo, projetos e tecnologias - do curso Tecnologias na Educação: ensinando e aprendendo com as TIC (100h), do Programa Nacional de Formação Continuada em Tecnologia Educacional (ProInfo Integrado) - de instigar e encorajar os cursistas a reconstruir uma concepção de currículo com a integração das TIC por meio da pedagogia de projetos é muito bem estruturada e atende à demanda de reestruturação da educação na sociedade do conhecimento, contemplando seu pilares constituintes. Entretanto, para se tornar uma prática pedagógica, deve ser compartilhada por todos os membros do corpo docente da escola - já que pressupõe a interdisciplinaridade - e de sua equipe diretiva - que na função de gestão deve coordenar o processo. O primeiro momento, constituído por uma auto avaliação do cursista de sua prática docente, assim como o segundo momento, a proposta de ação a partir da problematização da realidade discente e seus possíveis vínculos com o currículo se caracterizam em procedimentos já bastante disseminados na escola - apoiados por teorias pedagógicas como o construtivismo e o sócio-interacionismo - até mesmo por facilitarem o processo de ensino-aprendizagem. A inserção das TIC - proposta no segundo momento -, com o objetivo de facilitar a percepção do aluno com relação a sua realidade, ainda é subutilizada, limitando-se por vezes a usar um suporte tecnológico - datashow para a reprodução de slides, por exemplo - sem a produção efetiva de conhecimento sobre a realidade do aluno com o auxílio das TIC. Com a instrumentalização teórica no que concerne a integração das TIC ao currículo e os meios de concretizá-la, através da indicação de sites com importantes referências tais como textos e entrevistas com especialistas e estudiosos da área de educação e tecnologia, assim como com a instrumentalização técnica com a indicação de sites com materiais específicos - portal do professor, por exemplo - para uso de tecnologia como ferramenta pedagógica - sofwares como hagaquê, por exemplo -, o curso estimula a escola repensar a sua visão de currículo e o professor a sua prática docente, entretanto a viabilização da proposta de inserção das TIC na escola precisa ir além desta instrumentalização e fazer parte definitivamente do currículo e do projeto político pedagógico da escola. 


\section{Referências bibliográficas}

FLEURY, M. T.; OLIVEIRA JR., M. M. Gestão estratégica do conhecimento: integrando aprendizagem, conhecimento e competências. São Paulo: Atlas, 2001.

GUILE, D. O que distingue a economia do conhecimento? Implicações para a educação. In Cadernos de Pesquisa, v. 38, n. 135, set./dez., 2008

NONAKA, I.; TAKEUCHI, H. Criação de conhecimento na empresa: Como as empresas japonesas geram a dinâmica da inovação. Rio de Janeiro: Campus, 1997.

PRADO. M.E.B.B. Pedagogia de projetos: fundamentos e implicações. In: ALMEIDA, M.E.B.; MORAN, J.M. (Org.) Integração das tecnologias na Educação. Brasília: SEED, 2005.

SANCHEZ, R., HEENE, A. AND THOMAS, H. Towards the Theory and Practice of Competence-Based Competition. In SANCHEZ, R., HEENE, A. AND THOMAS, H. (Eds.) Dynamics of Competence-Based Competition. Oxford: Elsevier, 1996.

TORNAGUI, A.J.C; PRADO. M.E.B.B; ALMEIDA, M.E.B. Tecnologias na Educação: ensinando e aprendendo com as TIC. Proinfo - Curso 100h. Guia do Cursista. Brasília: MEC/SEED, 2011.

UNESCO. Padrões de Competência em TIC para professores. Módulos de Padrão de Competência. Paris, 2009.

ZANOTTO, M. A. do C.; DE ROSE, T. M. S. Problematizar a própria realidade: análise de uma experiência de formação contínua. In Educação e Pesquisa, v.29, n.1, p. 45-54, jan./jun., 2003. 